\title{
An investigation of a baroclinic depression that affected the area of Cyprus
}

\author{
K. Nicolaides ${ }^{1}$, K. Savvidou ${ }^{1}$, A. Orphanou ${ }^{1}$, S. C. Michaelides ${ }^{1}$, P. Constantinides ${ }^{1}$, C. Papachristodoulou ${ }^{1}$, and \\ M. Savvides ${ }^{2}$ \\ ${ }^{1}$ Meteorological Service, Nicosia, Cyprus \\ ${ }^{2}$ Department of Lands and Surveys, Nicosia, Cyprus
}

Received: 14 September 2007 - Revised: 20 December 2007 - Accepted: 25 February 2008 - Published: 9 April 2008

\begin{abstract}
The synoptic, dynamic, energetic and thermodynamic conditions during the development of a baroclinic depression which affected the area of Cyprus from 5 to 9 February 2006 are studied. The depression was associated with extreme weather phenomena such as thunderstorms, strong winds, dust and high precipitation accumulations (amounting to $50 \%$ of the mean monthly value). The results underline the importance of the dynamic control on the cyclone's development and the important contribution of the system itself in the energetics of the atmosphere. The thermodynamic analysis has proved a very useful tool in identifying the convective potential of the atmosphere at various stages of the development.
\end{abstract}

\section{Introduction}

The area of the east Mediterranean is situated in the transition zone between the subtropical latitudes which are characterized by the high pressure belt and the mid latitudes with the prevailing westerly flow. Consequently, the mid and upper level general circulation of the troposphere is the reason for the climatic characteristics of the area and there changes (Meteorological Office, 1962; Reiter, 1975; Radinovich, 1987; Jacobeit, 1987). Petterssen (1956) was the first to investigate the frequency of cyclonic depressions affecting the area of east Mediterranean. Flocas et al. (2001) concluded that the area of east Mediterranean is one of the three centers (Gulf of Genoa, South Italy and Cyprus area) of enhanced cyclonic action, while Macheras et al. (2002) noted that the characteristics of the centers of action are different and that they have a seasonal variability. The cyclonic frequency over the area is significantly enhanced during the cold

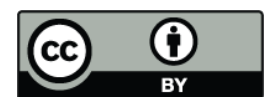

Correspondence to: K. Nicolaides (kleanthi@spidernet.com.cy) months. The synoptic, dynamic and energetic characteristics of other Mediterranean cyclones have also been examined elsewhere (Michaelides, 1987; Prezerakos and Michaelides 1989; Michaelides et al., 1999; Nicolaides et al., 2004a; Nicolaides et al., 2004b; Nicolaides, 2005; Nicolaides et al., 2006).

The objective of the present study is the profound investigation of the synoptic, dynamic, energetic and thermodynamic characteristics during the evolution of a baroclinic depression that affected the area of Cyprus from 5 to 9 February 2006. Such an analysis has both diagnostic and prognostic significance. This depression was chosen for study due to the severity of the associated weather phenomena. For instance, the resulting average precipitation over the mountainous region of the island was almost $130 \mathrm{~mm}$ and over the central plain area reached approximately $50 \mathrm{~mm}$. This is a quite significant precipitation accumulation during a single synoptic event, bearing in mind that the mean monthly precipitation for February is $81.6 \mathrm{~mm}$, for the country as a whole.

\section{Data and methodology}

In order to study the systems' spatial and temporal character, its dynamic, energetic and thermodynamic parameters were calculated for 00:00 UTC and for various isobaric layers of the period from 5 to the 9 February 2006. Results of the investigation were compared with results of investigation from other case studies.

The data used for the calculations of the dynamic and energetic fields are the NCEP/NCAR global analyses for 00:00 UTC, with a grid length of $2.5^{\circ} \times 2.5^{\circ}$. The area of the calculations is bounded by the meridians $20^{\circ} \mathrm{W}$ and $50^{\circ} \mathrm{E}$ and the parallel circles $20^{\circ} \mathrm{N}$ and $65^{\circ} \mathrm{N}$.

The dynamic parameters studied are the relative vorticity, the divergence of the horizontal wind vector, the vertical

Published by Copernicus Publications on behalf of the European Geosciences Union. 
(a)

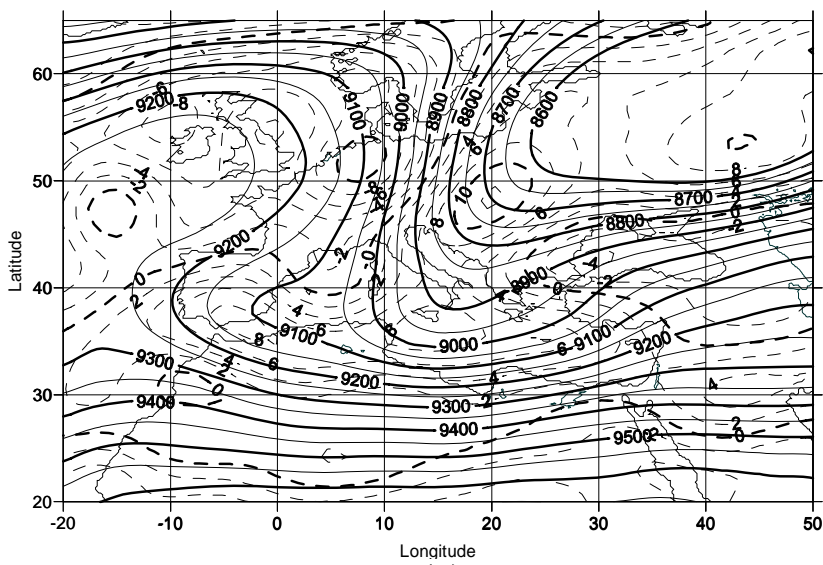

(b)

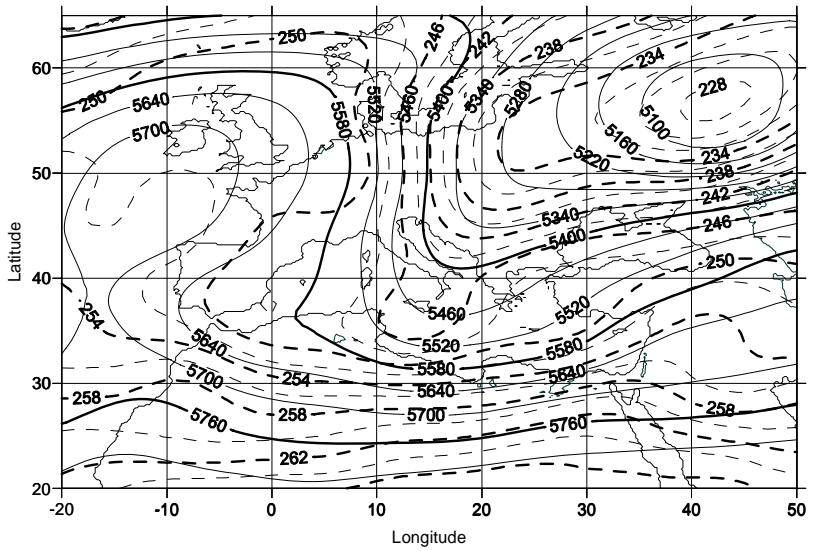

(c)

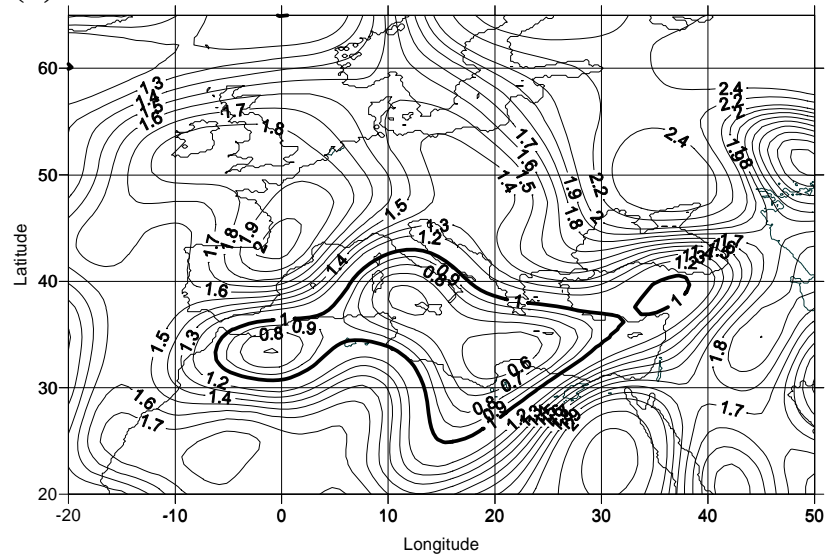

Fig. 1. Time D-1: (a) $300 \mathrm{hPa}$ geopotential height (solid lines, units: gpm) and relative vorticity (dashed lines, units: $10^{-5} \mathrm{~s}^{-1}$ ), (b) $500 \mathrm{hPa}$ geopotential height (solid lines, units: gpm) and temperature (dashed lines, units: K), and (c) $850 \mathrm{hPa}$ static stability parameter (units: $\left.\mathrm{K}^{2} \mathrm{~s}^{-1}\right)$.

motion and static instability (see Nicolaides et al., 2004 for a comprehensive mathematical presentation).

For the purpose of the energetic study, the zonal and eddy components of available potential and kinetic energies (ZAPE, ZKE, EAPE, EKE, respectively), their conversions and boundary energy transfers were also calculated (see Michaelides 1987 and 1992 for a thorough mathematical formulation and physical interpretation).

For the needs of the thermodynamic analysis, various thermodynamic indices were examined, using local radiosonde data, namely those of Athalassa radiosonde station $\left(35^{\circ}\right.$ $\left.09^{\prime} \mathrm{N}, 33^{\circ} 24^{\prime} \mathrm{E}\right)$. The definition and interpretation of the various thermodynamic parameters can be found online at http://www.crh.noaa.gov/lmk/soo/docu/indices.php).

For the synoptic investigation, synoptic charts, surface observations, satellite images, radar data were used.

\section{Synoptic outline}

An extensive low pressure system, with frontal activity and surface troughs, affected the areas of Central and Eastern Mediterranean and the Balkans, on the 6 February 2006. The low pressure system had two centres, one west of Peloponnesus (1005 hPa at 06:00 UTC) and the second over north Aegean (1004 hPa at 06:00 UTC), while over Cyprus the pressure field had values around $1013 \mathrm{hPa}$. Gradually, the low pressure moved to the east and the two centres of action merged at a new location south of Rhodes at 18:00 UTC with value $1003 \mathrm{hPa}$. No significant movement of the low was observed between 18:00 UTC on 6 February and 18:00 UTC on 7 February. Gradually, the low moved towards the northeast and deepened, reaching a central pressure value of $997 \mathrm{hPa}$ at 12:00 UTC on 8 February over southwest Turkey, while the pressure over Cyprus decreased to $1003 \mathrm{hPa}$. The depression started filling and moved to the east, while the pressure over Cyprus increased rapidly to $1012 \mathrm{hPa}$ at 12:00 UTC 
(a)

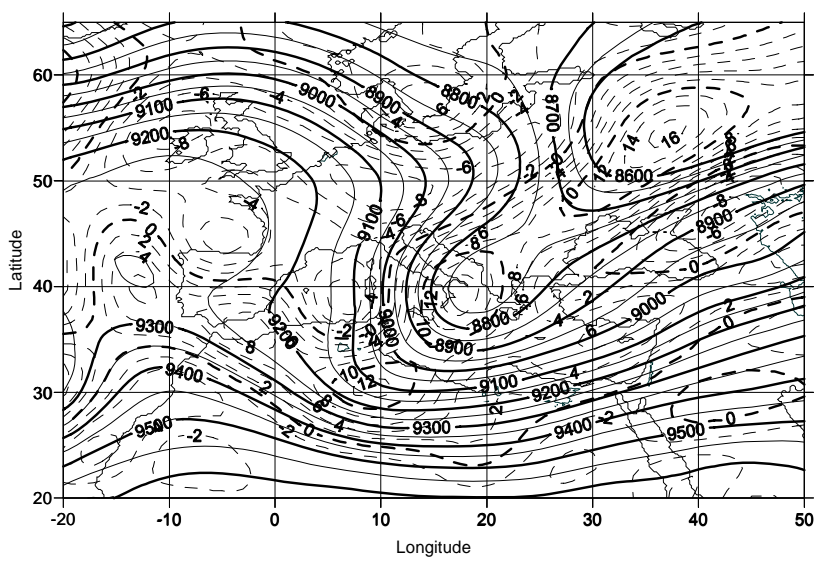

(b)

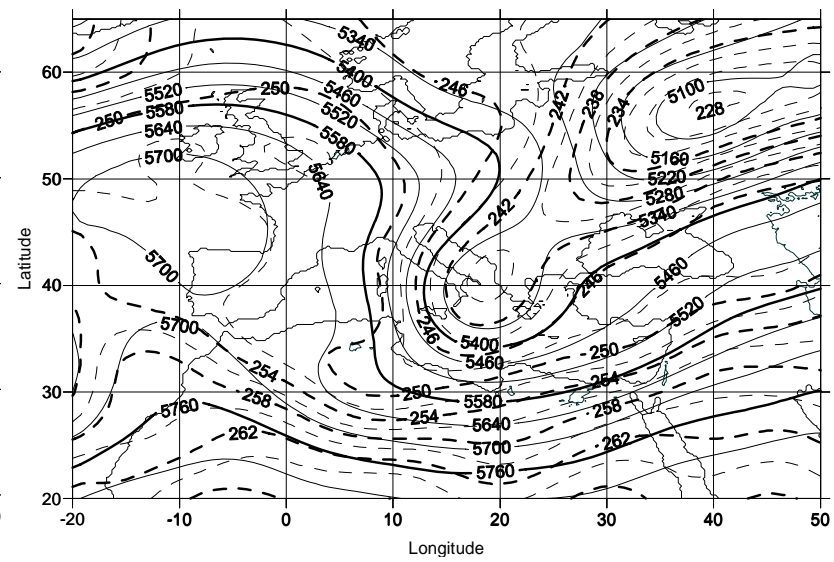

(c)

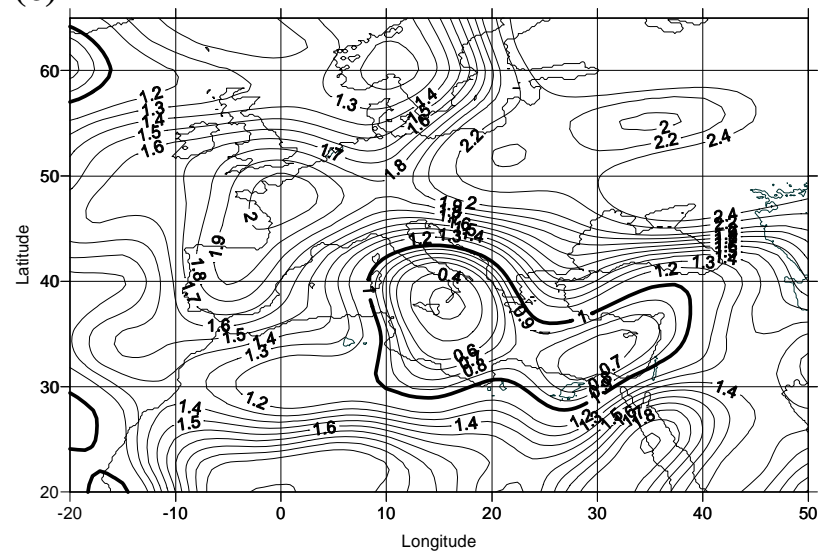

Fig. 2. Time D0: (a) $300 \mathrm{hPa}$ geopotential height (solid lines, units: gpm) and relative vorticity (dashed lines, units: $10^{-5} \mathrm{~s}^{-1}$ ), (b) $500 \mathrm{hPa}$ geopotential height (solid lines, units: gpm) and temperature (dashed lines, units: K), and (c) $850 \mathrm{hPa}$ static stability parameter (units: $\mathrm{K}^{2} \mathrm{~s}^{-1}$ ).

on 9 February. The pressure field over Cyprus noted a significant decrease, from $1014 \mathrm{hPa}$ to $1008 \mathrm{hPa}$, between 00:00 UTC and 16:00 UTC on 6 February.

\section{Dynamic analysis}

As stated earlier, results of the mathematical calculations correspond to the 00:00 UTC NCEP/NCAR analyses and were carried out for various isobaric levels for the times 5, 6, 7, 8 and 9 February 2006, which will be referred to in the following as D-2, D-1, D0, D+1 and D+2 respectively. For brevity, only some of the dynamic fields at the isobaric levels of 850 , 500 and $300 \mathrm{hPa}$ and for times D-1, D0 and D+1 are presented here.

The spatial distributions of the dynamic parameters at time D-1 are shown in Fig. 1. On the $300 \mathrm{hPa}$ isobaric surface (Fig. 1a); the upper trough extending from east Europe towards the Iberian Peninsula is associated with pronounced positive relative vorticity values. The maximum of relative vorticity is located just to north of the Balkans with a central value of more than $12 \times 10^{-5} \mathrm{~s}^{-1}$, noting the cyclonic behaviour of the upper troposphere, while the minimum of relative vorticity is over north Germany with a central value of less than $-10 \times 10^{-5} \mathrm{~s}^{-1}$, noting the anticyclonic behaviour of the upper troposphere. Over North Africa, the flow is westerly, turning to southwest over the east Mediterranean. A typical value of the geopotential height over Cyprus is $9175 \mathrm{gpm}$ (geopotential meters). At the same time, over the $500 \mathrm{hPa}$ isobaric surface (Fig. 1b), a trough is extending from northern of the Balkans towards the Iberian peninsula. The flow over the east Mediterranean is southwest, while over North Africa is again zonal. Typical height and temperature of the $500 \mathrm{hPa}$ isobaric surface over Cyprus are $5590 \mathrm{gpm}$ and $252 \mathrm{~K}$, respectively.

Looking at the distribution of the field of static stability values at the isobaric surface of $850 \mathrm{hPa}$ (Fig. 1c), low values of this parameter appear to characterize the maritime areas; with the lowest values over the Mediterranean implying 
(a)

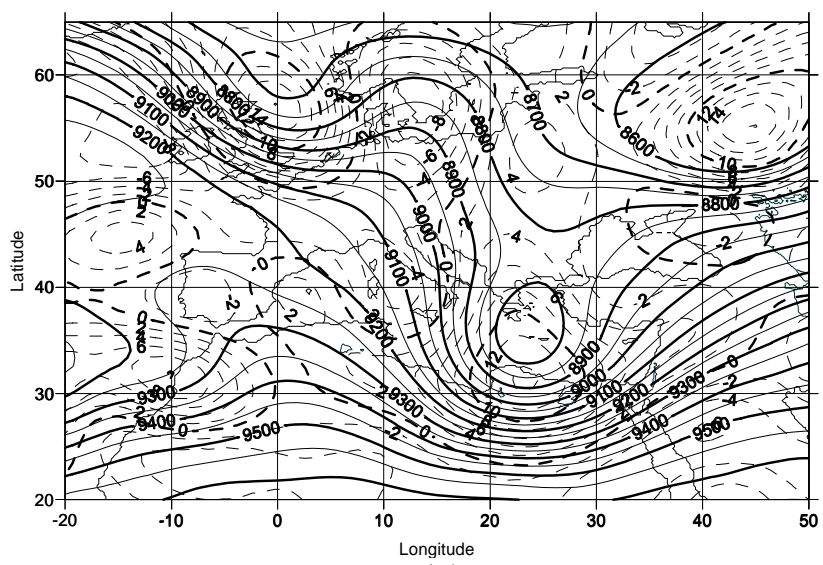

(b)

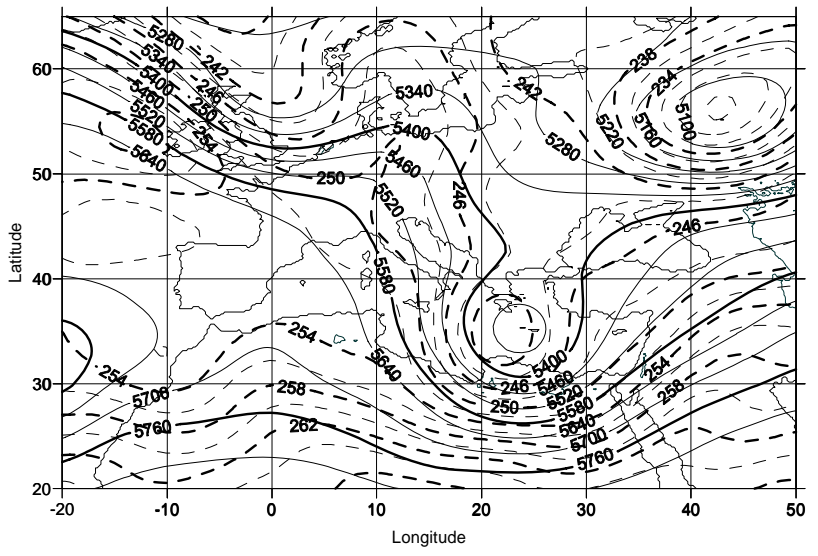

(c)

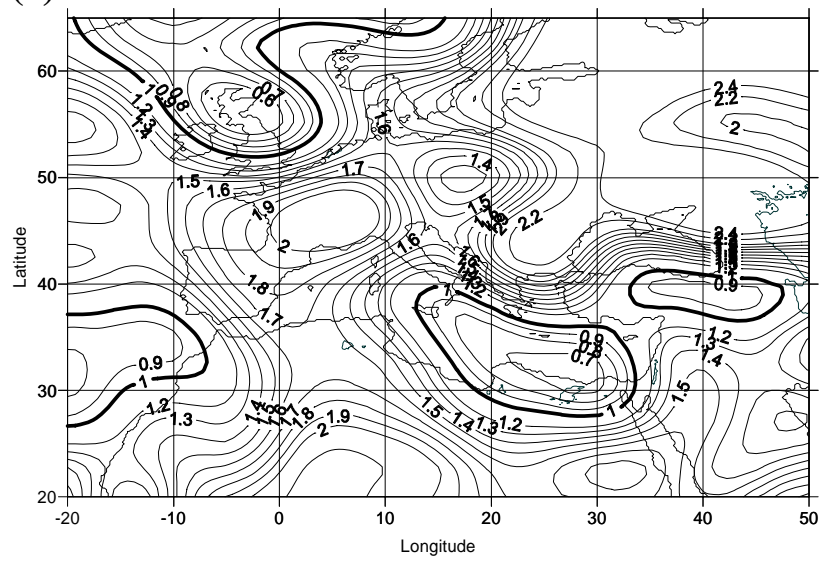

Fig. 3. Time D+1: (a) $300 \mathrm{hPa}$ geopotential height (solid lines, units: gpm) and relative vorticity (dashed lines, units: $10^{-5} \mathrm{~s}^{-1}$ ), (b) $500 \mathrm{hPa}$ geopotential height (solid lines, units: gpm) and temperature (dashed lines, units: K), and (c) $850 \mathrm{hPa}$ static stability parameter (units: $\left.\mathrm{K}^{2} \mathrm{~s}^{-1}\right)$.

increased lower tropospheric instability. The higher values, related to low level stability, are located over the continental regions.

Figure 2 displays the spatial distributions of the dynamic parameters at time D0. The upper trough, found earlier over the isobaric surface of $300 \mathrm{hPa}$, is extending from the Balkans towards Tunisia and west Mediterranean, while the area of the east Mediterranean remains in a relatively stronger southwesterly air flow (Fig. 2a). A typical value of the geopotential height over Cyprus at this time is $9075 \mathrm{gpm}$ which is by $100 \mathrm{gpm}$ lower than the height at time D- 1 . The maximum of relative vorticity is located to the north of Black Sea, with a central value of more than $16 \times 10^{-5} \mathrm{~s}^{-1}$, while local maxima are found over south Italy and just west of Cyprus, with central values of more than $12 \times 10^{-5} \mathrm{~s}^{-1}$ and $6 \times 10^{-5} \mathrm{~s}^{-1}$, respectively. The increased relative vorticity reflects the increased cyclonicity of the upper troposphere. Over the $500 \mathrm{hPa}$ isobaric surface (Fig. 2b), the trough covers almost the same area as over the $300 \mathrm{hPa}$ isobaric surface.
A typical value of the height of the $500 \mathrm{hPa}$ isobaric surface over the area of Cyprus is $5520 \mathrm{gpm}$ (i.e. $70 \mathrm{gpm}$ lower than the height at time D-1) and the temperature is $250 \mathrm{~K}$.

From the distribution of static stability index at $850 \mathrm{hPa}$ isobaric layer it is inferred that the Mediterranean, and mainly the east part and the region of south Italy, are the areas with the lowest static stability values reflecting to the increased lower tropospheric instability (Fig. 2c).

The spatial distributions of the dynamic parameters at time $\mathrm{D}+1$ are shown in Fig. 3. Over the $300 \mathrm{hPa}$ isobaric surface (Fig. 3a), an upper cut-off low is found over the Aegean, associated with an upper trough extending towards north Egypt. A typical value over Cyprus area is less than $9000 \mathrm{gpm}$ (more than $75 \mathrm{gpm}$ than at time D0, and more than $175 \mathrm{gpm}$ than at time D-1). The upper trough is associated with positive relative vorticity values related to the cyclonic behaviour of the upper troposphere. The maximum relative vorticity over the isobaric surface of $300 \mathrm{hPa}$ is found over the areas of north Egypt and north Libya having a central 

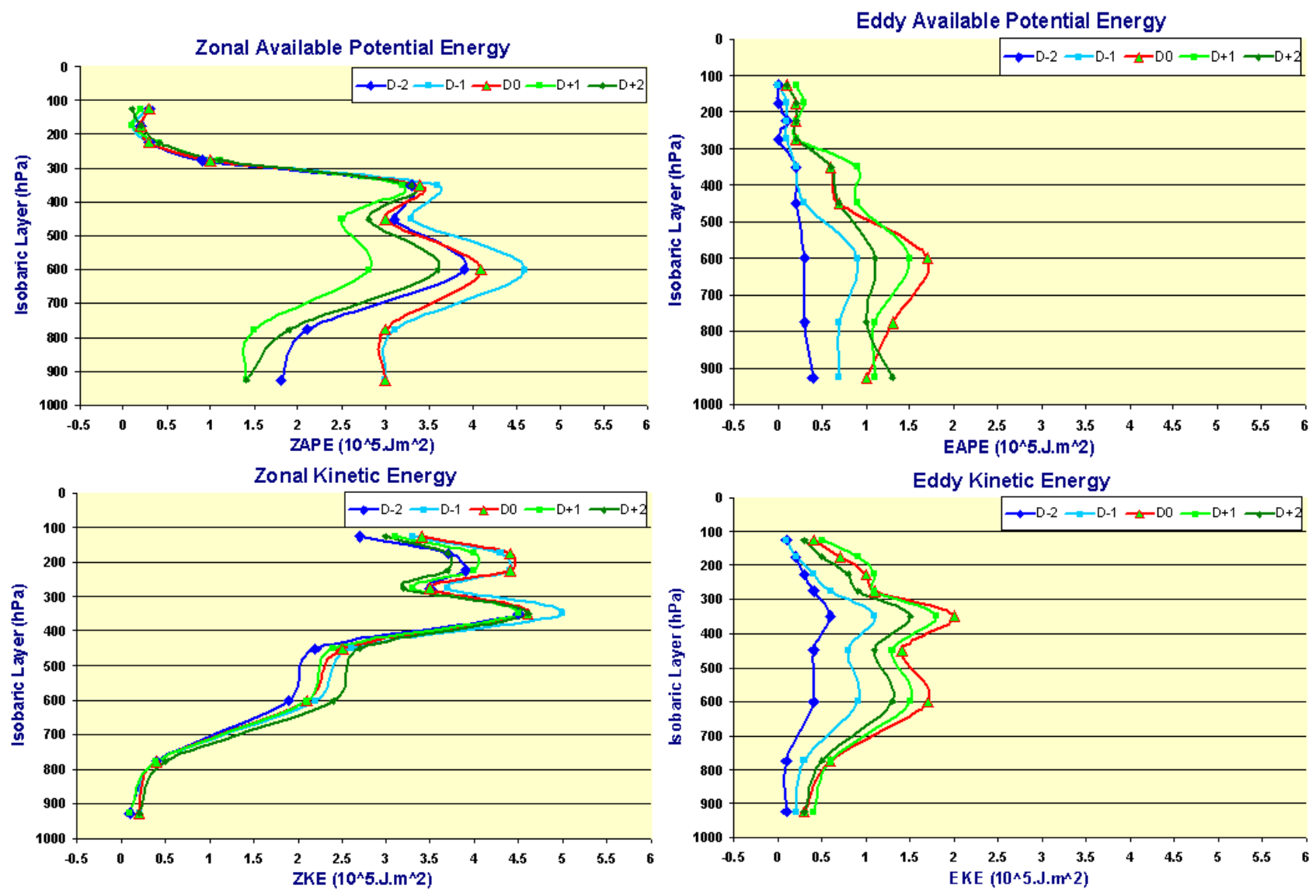

Fig. 4. Vertical distribution and time evolution of the four energy components (units: $10^{5} \mathrm{Jm}^{-2}$ ).

value of more than $14 \times 10^{-5} \mathrm{~s}^{-1}$, while over the area of Cyprus the relative vorticity is only reaching $3 \times 10^{-5} \mathrm{~s}^{-1}$. The cut-off low and the medium level trough $(500 \mathrm{hPa})$ are also found at the same position as over the $300 \mathrm{hPa}$ isobaric surface (Fig. 3b). The area of the east Mediterranean remains under a southwest medium level flow. A typical value of the height of the $500 \mathrm{hPa}$ isobaric surface over the area of Cyprus is at this time $5470 \mathrm{gpm}$ (50 gpm lower than the height at time D0 and $120 \mathrm{gpm}$ lower than the height at time D-1).

The static stability reveals that the area of the central and east Mediterranean is an area of lower tropospheric instability but, generally, the values do not reveal notable instability compared with time D0. In contrast with time D0, the static stability values exhibit a more stable lower troposphere over the area of Cyprus (Fig. 3c).

\section{Analysis of Energetics}

The components of an energy cycle as described by Michaelides (see Michaelides 1987 and 1992 for a thorough mathematical formulation and physical interpretation) have been calculated for the area of computation of the depression under study. The vertical distribution and the time evolution of the four forms of energy are shown in Fig. 4. The forms of energy studied are ZAPE, EAPE, ZKE and EKE. ZAPE has maximum values in mid (almost $4.5 \times 10^{5} \mathrm{Jm}^{2}$ at $600 \mathrm{hPa}$ at time D0) and upper troposphere (almost $3 \times 10^{5} \mathrm{Jm}^{2}$ at $350 \mathrm{hPa}$ at time D0) and very low values in the stratosphere, reflecting the significant level of baroclinicity in the former and substantial weakening of the baroclinicity in the latter (i.e. above $250 \mathrm{hPa}$ ). EAPE has again its greatest values over the mid troposphere (almost $1.5 \times 10^{5} \mathrm{Jm}^{2}$ at $600 \mathrm{hPa}$ at time D0). ZKE has high values at the jet stream level (more than $4.5 \times 10^{5} \mathrm{Jm}^{2}$ at around $350 \mathrm{hPa}$ ) which is slightly reduced over the lower stratosphere (less than $4.5 \times 10^{5} \mathrm{Jm}^{2}$ at around $200 \mathrm{hPa}$ ). The eddy energy components EKE and EAPE, exhibit a gradual increase from 5 to 7 of February and then a gradual decrease till the 9 February.

The conversions from one type of energy to another that took place within the system are presented in Fig. 5. The amount of energy conversion from ZKE to EKE exhibits a gradual increase from the 5 to 7 February and then a gradual decrease till 9 February. ZKE is converted to ZAPE, at all times, with the exception of the 7 February, when a reverse conversion is noted. The conversion between ZAPE 
Table 1. The values of various instability indices. *: Weak probability for convection, **: Moderate probability for convection, ***: Strong probability for convection.

\begin{tabular}{llllll}
\hline & $\mathrm{D}-2$ & $\mathrm{D}-1$ & $\mathrm{D} 0$ & $\mathrm{D}+1$ & $\mathrm{D}+2$ \\
\hline $\mathrm{TT}\left({ }^{\circ} \mathrm{C}\right)$ & $35.6^{*}$ & $44.6^{*}$ & $53.0^{* *}$ & $43.4^{*}$ & $48.2^{* *}$ \\
$\mathrm{LI}\left({ }^{\circ} \mathrm{C}\right)$ & $5.8^{*}$ & $-3.0^{* *}$ & $-2.8^{*}$ & $0.0^{*}$ & $-0.5^{*}$ \\
$\mathrm{KI}\left({ }^{\circ} \mathrm{C}\right)$ & $15.0^{*}$ & $12.7^{*}$ & $23.3^{*}$ & $15.7^{*}$ & $0.9^{*}$ \\
$\mathrm{SI}\left({ }^{\circ} \mathrm{C}\right)$ & $11.2^{*}$ & $6.0^{*}$ & $1.9^{* *}$ & $4.4^{*}$ & $5.4^{*}$ \\
$\mathrm{KO}\left({ }^{\circ} \mathrm{C}\right)$ & $2.7^{* *}$ & $-4.4^{* * *}$ & $-4.0^{* * *}$ & $-0.6^{* * *}$ & $-1.0^{* * *}$ \\
$\mathrm{CAPE}(\mathrm{J} / \mathrm{Kg})$ & - & $626^{*}$ & $414^{*}$ & $138^{*}$ & $100^{*}$ \\
$\mathrm{CAPE} 0-\mathrm{xm}(\mathrm{J} / \mathrm{Kg})$ & - & $183^{* *}$ & $93^{*}$ & $53^{*}$ & $49^{*}$ \\
$\mathrm{BRN}$ & - & $3^{*}$ & $5^{*}$ & $2^{*}$ & $8^{*}$ \\
$\mathrm{BRNshear}$ & $8.5^{* *}$ & $14.6^{* * *}$ & $8.7^{* *}$ & $9.6^{* *}$ & $8^{* *}$ \\
VGP & - & $.345^{* *}$ & $.289^{* *}$ & $0.109^{* *}$ & $0.086^{*}$ \\
$\mathrm{WBZ}(\mathrm{ft})$ & $4904^{*}$ & $4312^{*}$ & $5172^{* *}$ & $2749^{*}$ & $3068^{*}$ \\
$\mathrm{CAP}$ & $-1.0^{* * *}$ & $-0.3^{* * *}$ & $1.5^{* *}$ & $0.1^{* * *}$ & $-0.2^{* * *}$ \\
$\mathrm{SWEAT}$ & $41^{*}$ & $183^{*}$ & $227.9^{*}$ & $167.0^{*}$ & $81^{*}$ \\
$\mathrm{EHI}$ & - & - & $.5^{*}$ & $0.1 * * *$ & $0.0^{*}$ \\
$\mathrm{~S}$ index & $26.1^{*}$ & $35.6^{*}$ & $48.0^{* * *}$ & $43.4^{* *}$ & $28.2^{*}$ \\
Boyden Index & $95.9^{* *}$ & $97.4^{* *}$ & $96.9^{* *}$ & $95.8^{* *}$ & $94.2^{* *}$ \\
$\mathrm{CTT}\left({ }^{\circ} \mathrm{C}\right)$ & & -35.5 & -34.5 & -29.9 & -37.7 \\
$\mathrm{FZ}(\mathrm{ft})$ & 5907 & 6564 & 6409 & 4435 & 4455 \\
EL-FL(ft) & & 17381 & 16051 & 13613 & 16992 \\
\hline
\end{tabular}
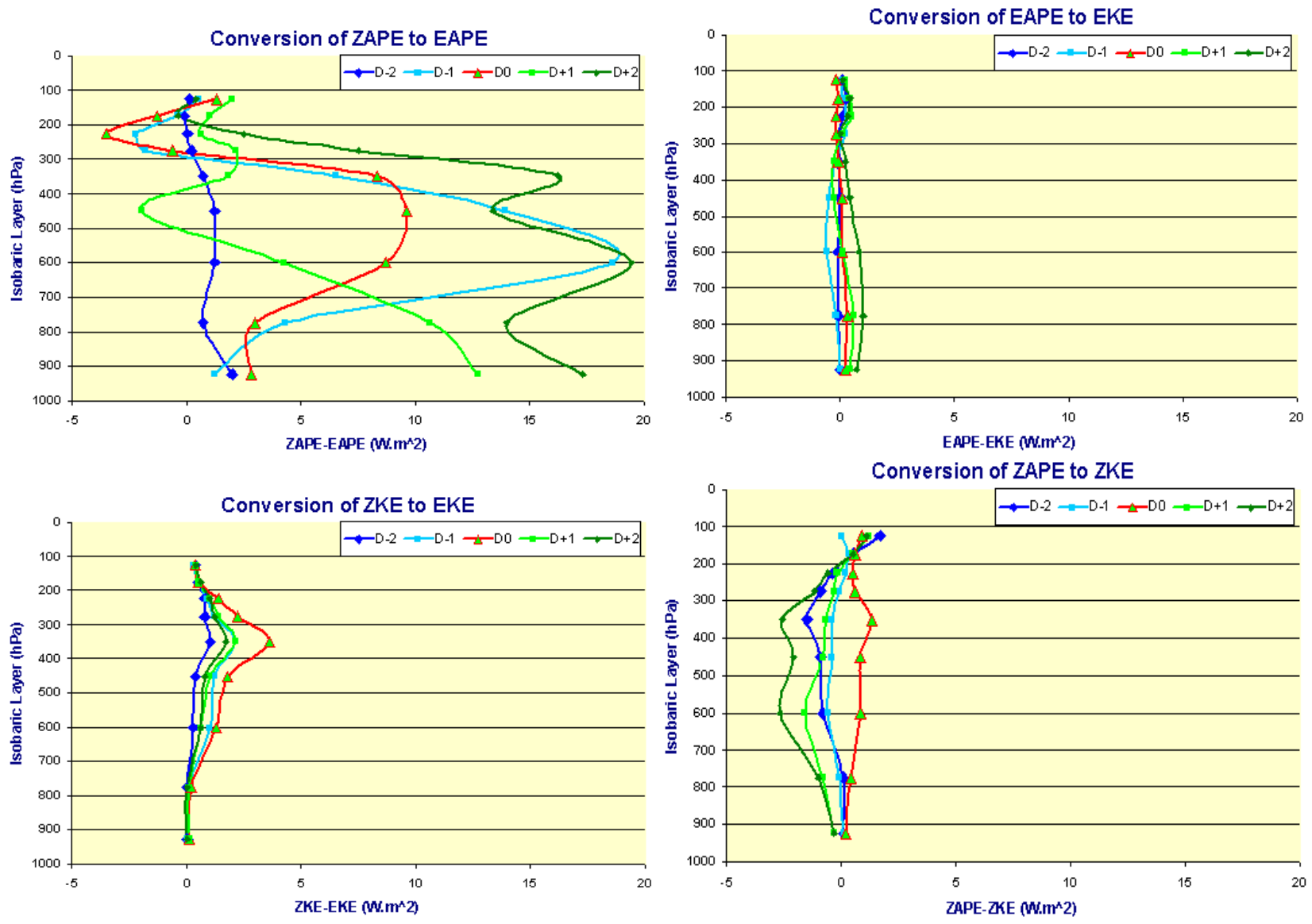

Fig. 5. Vertical distribution and time evolution of the four energy conversions (units: $\mathrm{Wm}^{-2}$ ). 

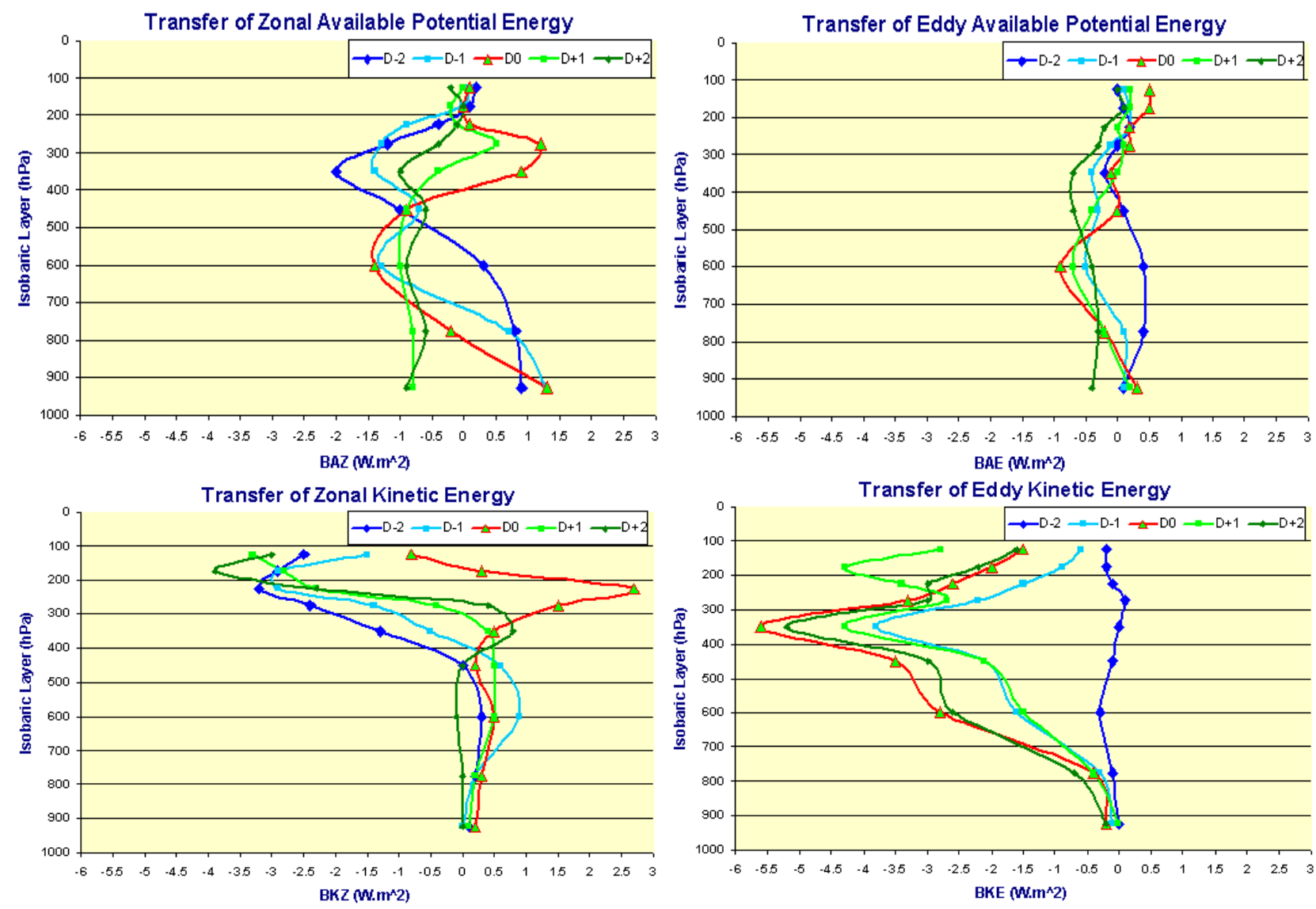

Fig. 6. Vertical distribution and time evolution of the four energy boundary transfers (units: $\mathrm{Wm}^{-2}$ ).

and EAPE is insignificant initially, but later considerable amounts of ZAPE are converted into EAPE, mainly in the troposphere; the reverse appears to occur in the stratospheric layers. The zonal kinetic energy appears to supply the eddy component at all times, with the maximum of this conversion taking place at the jet stream level (i.e. at $350 \mathrm{hPa}$ ). Finally, the conversion of EAPE to EKE is very close to zero, although small amounts of EAPE seem to be converted into EKE on 7, 8 and 9 February.

The energy transfers to and from the open area surrounding the synoptic system in study are displayed in Fig. 6. Significant amounts of EKE are extracted from the system at all times with maximum values at the level of $350 \mathrm{hPa}$ (almost $-5.5 \times \mathrm{Wm}^{2}$ at time D0). Small amounts of ZKE in the lower and mid troposphere enter at all times the system's area and large amounts are extracted in upper troposphere and stratosphere, except on 7 February, when ZKE continues to gain energy from the surrounding environment throughout the troposphere.

\section{Thermodynamic analysis}

The thermodynamic behavior of the troposphere for the period from 5 to 9 February was examined through a set of instability indices. The instability indices were calculated from the radiosounding data of Athalassa station at 12:00 UTC and displayed in Table 1.

Most of the indices exhibited an increase during the period, implying that the potential of the troposphere to give thunderstorms increases with the evolution of the system. Especially, the KO index obtained values between -0.6 and -4.4 , indicating that the atmosphere had the potential to produce severe thunderstorms. The CAPE index attained values between 1.5 and -0.3 , which means that the atmosphere had the potential for convective activity. The level of the WetBulb zero isotherm was found at $1650 \mathrm{~m}$ on the 7 of February, denoting a moderate probability for hail to reach the ground.

The values of BRNshear ranged between 8 and 14.6, indicating a moderate to strong probability of the atmosphere to sustain tornadic supercells. The cloud top temperature (CTT) and the vertical extend (EL-FZ) of the convective cloud above freezing level (FZ) suggest moderate thunderstorms with hail.

The passage of the depression from the area of Cyprus 
caused the gradual cooling of the air mass, by about $6^{\circ} \mathrm{C}$ at $850 \mathrm{hPa}$ and about $11^{\circ} \mathrm{C}$ at $500 \mathrm{hPa}$ justifying the instability that was exhibited in the area.

\section{Concluding remarks}

The development and evolution of a synoptic disturbance which affected the area of Cyprus between 5 and 9 February 2006 were studied. The system developed over central Mediterranean and amplified just to the west of Cyprus.

The upper level isobaric circulation is characterized by a trough of longer wavelength during the period immediately before the maximum deepening of the surface cyclone (i.e. at times D-2 and D-1); the wavelength shortens and the amplitude increases, as the system deepens. The most intense baroclinic features of the depressions were found at times D0 and $\mathrm{D}+1$. The advection of positive relative vorticity seems to be crucial in the stages preceding the time of maximum cyclone deepening. The noticeable advection of relative vorticity just to the west of Cyprus during these stages, led to further deepening of the cyclone and subsequent transfer into the study area. The dynamics within the troposphere contributed to the development and occurrence of dynamic and convective weather phenomena over Cyprus. A strong dependence of the static stability index and geographical factors (i.e. maritime and continental regions) was noted. It seems that during the cold season, the Mediterranean warmer sea waters, as well as the low level release of latent heat, largely control the stability characteristics of the troposphere and act as triggering mechanisms for lower tropospheric convergence. From the comparison of the findings of the dynamic investigation of this depression with the findings from previous studies over the area of Cyprus (e.g. Nicolaides et al., 2004a; Nicolaides et al., 2004b; Nicolaides, 2005) it is found that it does not comprise an exceptional case. It was a rather common system and its dynamic characteristics are similar to those of depressions affecting the area from the west direction (note that the vast majority of the depression affecting the area of the east Mediterranean are depressions from the west direction, see Nicolaides, 2005).

The thermodynamic indices pointed out the existence of instability and some of them suggest prevailing thunderstorms, tornadic activity and hail storms.

ZAPE obtains maximum values in the middle and upper troposphere at time D0. The maxima were observed at the $600 \mathrm{hPa}$ and $300 \mathrm{hPa}$ isobaric levels. The very low values in the stratospheric layers reflect the substantial weakening of the depression's baroclinicity. The eddy energies have their maximum values also at time D0. Significant energy conversions take place mainly at the isobaric levels of $600 \mathrm{hPa}$ and $300 \mathrm{hPa}$, while the most significant conversion is that of ZAPE to EAPE at time D+2. The boundary transfers of energies are mainly observed around the $200 \mathrm{hPa}$ and the $350 \mathrm{hPa}$ isobaric levels, while the most significant transfer is that of eddy kinetic energy at time D0 at the $350 \mathrm{hPa}$ isobaric level.

Acknowledgements. This study was undertaken within the framework of project "FLASH" which is funded by the European Union (Sixth Framework Programme, Contract No. 036852).

Edited by: S. C. Michaelides

Reviewed by: two anonymous referees

\section{References}

Meteorological Office: Weather in the Mediterranean., Vol. I, 2nd edition, HMSO: London, 1962.

Reiter, E. R.: Handbook for forecasters in the Mediterranean, Naval Postgraduate School, Monterey California, USA, 1975.

Radinovic, D.: Mediterranean cyclones and their influence on the weather and climate, program on short and medium range weather prediction research (PSMP), W.M.O. Sofia, 132 pp., 1987.

Jacobeit, J.: Variations of trough position and precipitation patterns in the Mediterranean Area, J. Climatol., 7, 453-476, 1987.

Petterssen, S.: Weather analysis and forecasting, McGraw-Hill, 1956.

Maheras, P., Flocas, H. A., Anagnostopoulou, C., and Patrikas, I.: On the vertical structure of composite surface cyclones in the Mediterranean region, Theor. Appl. Climatol., 71, 199-217, 2002.

Flocas, H. A., Maheras, P., Karacostas, T. S., Patrikas, I., and Anagnostopoulou, C.: A 40-year Climatological study of relative vorticity distribution over the Mediterranean, Int. J. Climatol., 21, 1759-1778, 2001.

Michaelides, S. C.: Limited area energetics of Genoa cyclogenesis, Mon. Weather Rev., 115, 13-26, 1987.

Prezerakos, N. G. and Michaelides, S. C.: A composite diagnosis in sigma coordinates of the atmospheric energy balance during intense cyclone activity, Q. J. Roy Met. Soc., 115, 463-486, 1989.

Michaelides, S. C.: A spatial and temporal energetics analysis of a baroclinic disturbance in the Mediterranean, Mon Weather Rev, 120, 1224-1243, 1992.

Michaelides, S., Evripidou, P., and Kallos, G.: Monitoring and predicting Saharan Desert Dust events in the Eastern Mediterranean, Weather, 54, 359-365, 1999.

Nicolaides, K., Michaelides, S., and Karacostas, T.: Spatial distribution of some dynamic parameters during the evolution of selected depressions over the area of Cyprus, Int. J. Climatol., 24, 1829-1844, 2004a.

Nicolaides, K., Michaelides, S., and Karacostas, T.: Statistical characteristics of the cold season depressions over the area of Cyprus, Meteorological Journal, 7, 61-66, 2004b.

Nicolaides, K.: Synoptic and dynamic study of the depression cases affected the wider area of Cyprus during cold months, $\mathrm{PhD}$ thesis, Aristotelian University, Thessaloniki, Greece (in Greek), 2005.

Nicolaides, K., Michaelides, S., and Karacostas, T.: Synoptic and dynamic characteristics of selected deep depressions over Cyprus, Adv. Geosci., 7, 195-180, 2006, http://www.adv-geosci.net/7/195/2006/. 